\title{
Bacteriological and Serological Studies of Fast Growing Mycobacteria Identified as Mycobacterium friedmannii
}

\author{
By J. L. STA NFORD \\ Department of Bacteriology, Guy's Hospital Medical School, London S.E. I \\ AND A. BECK \\ Department of Pathology, St. Mary's Hospital, London W.9 \\ (Accepted for publication I I June I969) \\ SUMMAR Y \\ Three recently isolated strains of a fast growing non-pigmented mycobac- \\ terium, two of which were from a series of injection abscesses and one which \\ was recovered from a water tank, have been compared bacteriologically and \\ serologically in gel-diffusion tests with a number of mycobacterial type \\ strains. The three strains and type strains of $M$. abscessus, $M$. runyonii, $M$. \\ borstelense and $M$. friedmannii were of one species. This species differed in \\ several respects from $M$. ranae (fortuitum), $M$. smegmatis and $M$. thamno- \\ pheos. In view of the chronological priority of $M$. friedmannii over the other \\ names, we recommend that this name be adopted as the correct designation \\ for this species. The origin of the type strain of $M$. friedmannii is discussed \\ and reasons are given for its acceptance as representative of Friedmann's \\ original strains.
}

\section{INTRODUCTION}

In 1967 two strains of a fast growing non-pigmented mycobacterium isolated from a series of injection abscesses occurring in Hartlepool were sent to us for identification. During our investigation of the outbreak, reported elsewhere (Inman, Brown, Beck \& Stanford, 1969) we found that these strains were identical with a type strain of Mycobacterium abscessus. Further studies revealed that this identity extended to the type strains of several other allegedly different species. This paper records our investigations into the identity of all these strains, and a comparison between this group of strains (the 'test' strains) and representatives of three well established species of fast growing non-pigmented mycobacteria.

\section{METHODS}

Bacteria. The test strains were I.W. and B.в. from the Hartlepool outbreak of injection abscesses; w.T., isolated from a cold water tank supplying the laboratory of one of the authors (A.B.); Mycobacterium abscessus ATCC I9977; M. borstelense and $M$. borstelense var. niacinogenes, received from Dr R. Muser (Heidelberg); M. runyonii NCTC $10269 ; M$. fortuitum NCTC 946 (this was originally the type strain of $M$. friedmannii but Gordon \& Smith (1955) reclassified it as $M$. fortuitum).

The strains used for comparison were $M$. fortuitum NCTC 8573 ; C.U. and J.C., 
isolated before from abscesses (Beck, 1965); M. smegmatis NCTC 333; M. thamnopheos ATCC 4445 .

Stanford \& Gunthorpe (1969) have shown $M$. ranae to be identical with $M$. fortuitum and to have chronological priority over it. Therefore the name $M$. ranae (fortuitum) will be adopted in the present paper to avoid confusion.

Bacteriological tests. Bacterial morphology was studied in Ziehl-Neelsen stained films of organisms taken from one-week-old cultures on Löwenstein-Jensen medium. Colonial appearances were examined on the same medium and cultures were incubated at $4,20,32,37$ and $45^{\circ}$ for studies of growth at different temperatures.

The cultures were examined for: production of catalase (Middlebrook, 1954); nitrate reductase (Virtanen, I960); arylsulphatase within 3 days (Whitehead, Wildy \& Engbaek, 1953); Tween 80 degradation within 5 days (Wayne, 1962); growth on Löwenstein-Jensen medium containing $10 \mu \mathrm{g}$. thiosemicarbazone $/ \mathrm{ml}$; ; growth on semi-solid agar (Marks \& Richards, I962); amidase activity (Bönicke, 1962); utilization of sugars and acids (Gordon \& Smith, I953). The amidase and acid utilization tests were done several times because of difficulties of interpretation; the results reported are those in which a majority of agreement was obtained. Sensitivity tests to isoniazid, streptomycin, $p$-aminosalicylic acid (PAS), cycloserine and ethionamide were done as described by Beck (1965). Sensitivity to ethambutol was tested on Löwenstein-Jensen medium containing 0.5, I, 2, 4, 8 and I6 $\mu \mathrm{g}$. drug $/ \mathrm{ml}$.

Serological tests. The serological methods were basically those of Stanford \& Beck (1968). An extract was produced from each strain by freezing and disintegrating in an 'X-press' the harvested pellicles of cultures in a modified Sauton medium (Boyden \& Sorkin, 1955). Antisera were produced in pairs of rabbits to Mycobacterium abscessus strain ATCC 19977, to $M$. runyonii strain NCTC 10269, and to strains I.W. and B.B., by a series of intramuscular injections of bacterial extract suspended in an equal volume of a mixture of 8.5 parts Bayol $\mathrm{F}$ and $\mathrm{I} .5$ parts Arlacel. Each of the extracts was examined in double gel-diffusion tests in agar against each of the antisera. Representative extracts of our strains were also examined against antisera to $M$. smegmatis, $M$. ranae (fortuitum) and $M$. thamnopheos available from other studies.

Absorption of antisera was performed in some cases. Samples of antisera were mixed with equal volumes of bacterial extract and incubated at $4^{\circ}$ for 24 to $48 \mathrm{hr}$. They were then examined in gel-diffusion tests against the bacterial extracts which had been used for immunization and those used for absorption. The antiserum to strain I.W. was absorbed with bacterial extracts of strains I.W., ATCC I9977, NCTC I0269 and C.U. The antiserum to ATCC 19977 was absorbed with its autologous extract and strain NCTC 10269.

\section{RESULTS}

Bacteriological examinations. The majority of strains showed a smooth shiny growth, but the cultures of Mycobacterium friedmannii NCTC 946, $M$. runyonii NCTC I0269, $M$. ranae (fortuitum) J.C. and $M$. thamnopheos ATCC 4445 were rough and dull. No pigment was formed in the dark or after exposure to light.

The strains consisted of bacilli of medium length, except for the Mycobacterium ranae (fortuitum) strains J.C. and NCTC 8573 which were short bacilli. Strains which produced smooth colonies were easily emulsified and showed a fairly homogeneous distribution of organisms in stained smears, whereas the rough strains showed a 
tendency to clump or form thin loose strands. The degree of fastness to acid ethanol varied. A few strains showed a preponderance of bacilli not fast to acid ethanol; of these $M$. thamnopheos was most notable.

Heavy growth was obtained in 2 to 3 days at $20^{\circ}, 32^{\circ}$ and, with the exception of Mycobacterium thamnopheos, at $37^{\circ}$. Only $M$. smegmatis grew at $45^{\circ}$; contrary to Friedmann's findings none of the strains grew at $4^{\circ}$. The recently isolated strains

Table I. Biochemical reactions of mycobacterial strains

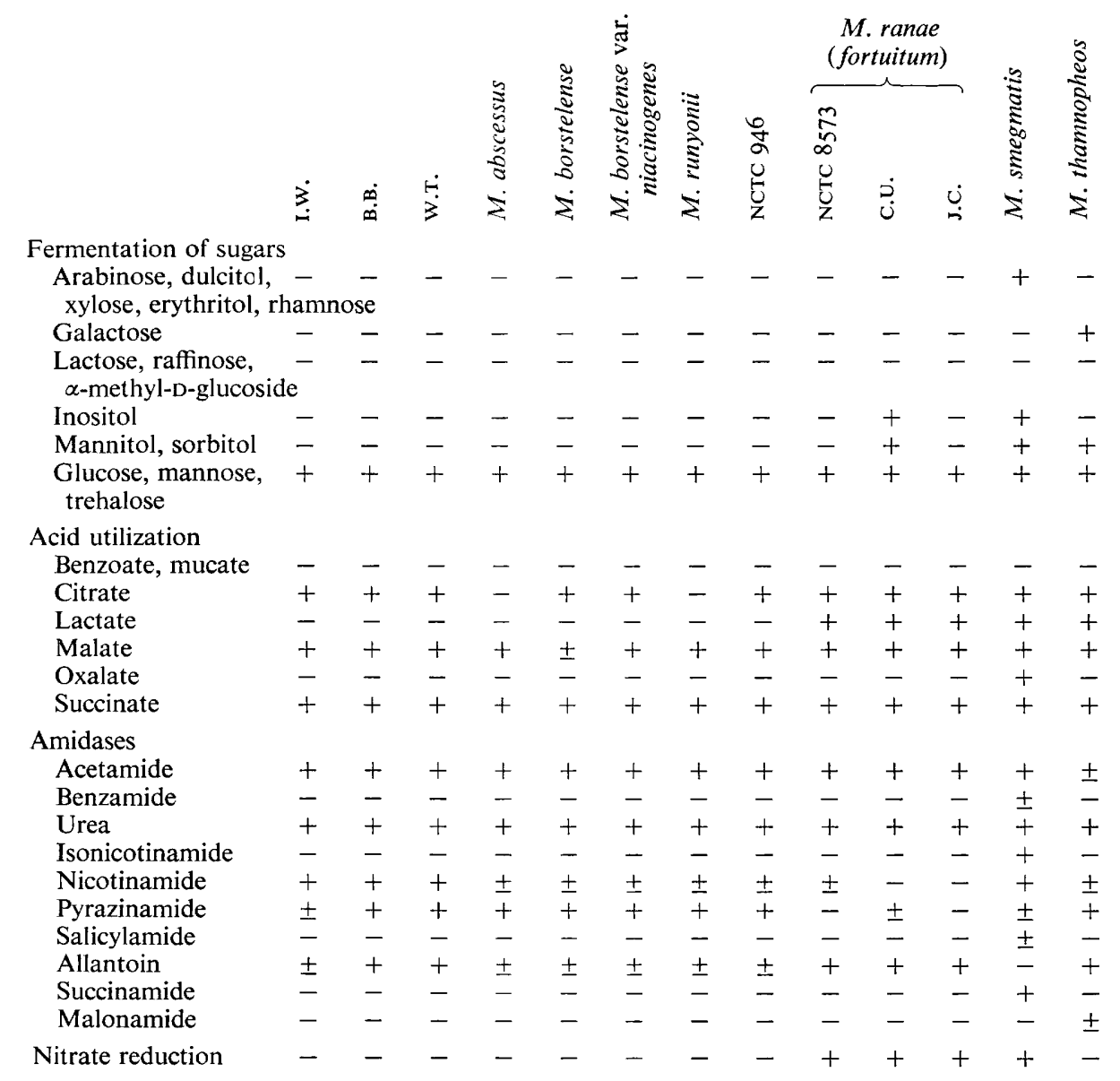

(I.W., B.B., W.T.) initially grew better at temperatures slightly below $37^{\circ}$. The organisms grew on Löwenstein-Jensen medium, nutrient agar, blood agar, Sabouraud glucose agar, and on the surface of semi-solid agars. The $M$. ranae (fortuitum) strains grew vigorously on MacConkey agar in which they produced strong acid; the other strains produced little or no acid. With the exception of the $M$. borstelense var. niacinogenes strain none of the strains produced nicotinic acid. They all gave a strong catalase reaction and all, except $M$. thamnopheos and $M$. smegmatis, a positive arylsulphatase test after incubation for 3 days. Only strains of $M$. thamnopheos and 
$M$. smegmatis hydrolysed Tween 80 within 5 days; weak hydrolysis of this substance occurred on prolonged incubation with some of the other strains.

The results of the nitrate reductase, amidase, fermentation of sugars and utilization of organic acids tests are given in Table $I$ and those of the drug sensitivity tests in Table 2.

Serological examinations. Extracts of the eight test strains produced the same pattern of twelve precipitation lines with antisera to two of them (I.W. and B.B.). Similar patterns of lines, though of slightly fewer number, were obtained with antisera to strains NCTC I0269 and ATCC 19977. Extracts prepared from the strains of the other

Table 2. Drug sensitivity of mycobacterial strains expressed as resistance ratio (ratio of m.i.c. of test strain to m.i.c. of strain $\mathrm{H}_{37} \mathrm{Rv}$ )

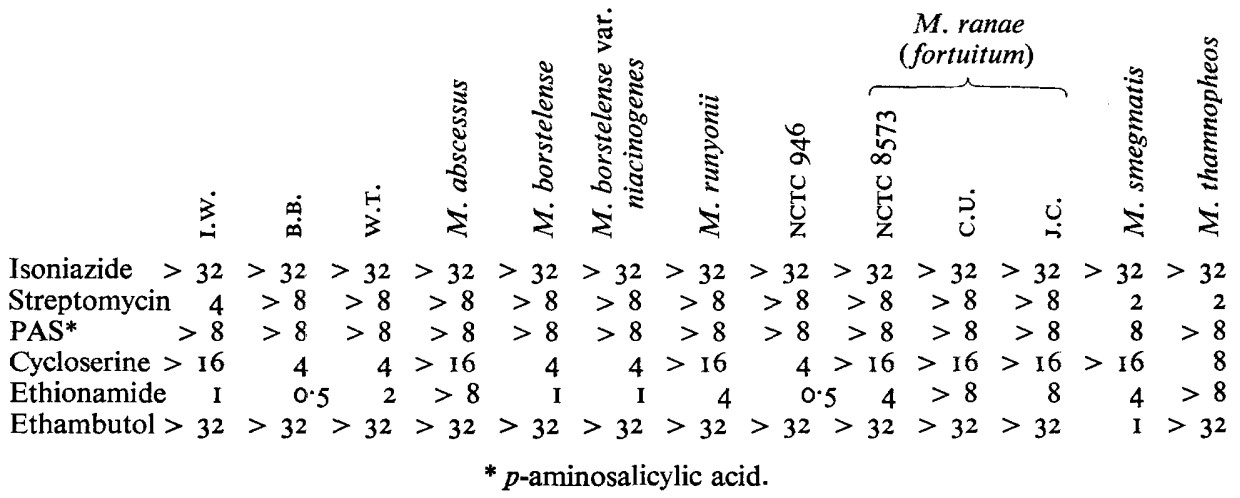

three species selected for comparison shared only six lines of precipitation with the test strains. The same six lines alone were seen when extracts of representative test strains were examined with antisera to strains of Mycobacterium ranae, M. smegmatis and $M$. thamnopheos. When tested against extracts of the homologous strains each of these sera produced some additional lines. Absorption of the antisera to strains I.W. and ATCC I 9977 with extracts of the test strains removed all precipitins, whereas absorption with the $M$. ranae (fortuitum) extract left intact those antibodies which were specific to the test strains.

\section{DISCUSSION}

The results of the bacteriological and serological examinations showed that the strains from the Hartlepool outbreak of injection abscesses, the strain isolated from a water tank and the type strains of Mycobacterium abscessus, $M$. borstelense, $M$. runyonii and strain NCTC 946 were identical in most respects, and that they differed from $M$. ranae (fortuitum), $M$. smegmatis and $M$. thamnopheos. There were no consistent differences of bacterial or colonial morphology to distinguish between any of the strains tested. Nor did growth at different temperatures allow any distinction, with the exceptions of $M$. thamnopheos, which would not grow at $37^{\circ}$, and $M$. smegmatis, which alone grew at $45^{\circ}$. Of the biochemical tests the sugar fermentation, organic acid utilization and amidase tests readily distinguished $M$. smegmatis from the other strains by its greater enzymic activity. It was, however, more difficult to distinguish between 
the other species. The most consistent properties by which the eight test strains differed from $M$. ranae (fortuitum) were their inability to reduce nitrate and to utilize lactate. Less consistent were the minor differences of the amidase spectra of the two groups. $M$. thamnopheos could be distinguished from all the other strains by its ability to ferment galactose; it shared with $M$. smegmatis the ability to hydrolyse Tween 80 within 5 days, and the lack of arylsulphatase activity.

In the sensitivity tests all strains except Mycobacterium smegmatis and $M$. thamnopheos were resistant to streptomycin, p-aminosalicylic acid (PAS) and isoniazid and, with the exception of $M$. smegmatis, also to ethambutol. All strains were fully or doubtfully resistant to cycloserine. Most strains were sensitive or only doubtfully resistant to ethionamide, but one of the test strains ( $M$. abscessus) and three of the strains used for comparison were completely resistant to this compound. All strains were resistant to io $\mu \mathrm{g}$. thiosemicarbazone $/ \mathrm{ml}$.

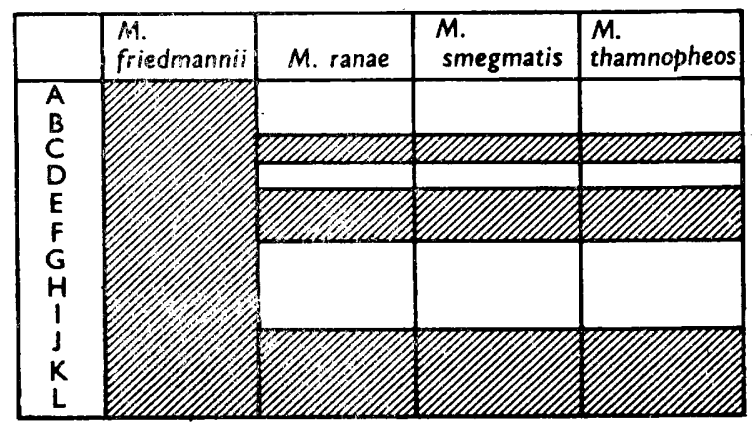

Fig. I. Results of double diffusion precipitation tests with antisera to strains of Mycobacterium friedmannii and antigen extracts of $M$. friedmannii, $M$. ranae (fortuitum), $M$. smegmatis and M. thamnopheos. The letters A to $\mathrm{L}$ represent the immunoprecipitate lines in the order in which they fell between antigen and antiserum wells in the majority of tests.

Serologically the group of eight test strains behaved identically, in gel diffusion producing with the antisera to four of them up to six lines of precipitation specific to themselves, and another six lines which they shared with Mycobacterium ranae (fortuitum), M. smegmatis and $M$. thamnopheos (Fig. I). Four of the latter lines corresponded to the common mycobacterial antigens described by Stanford \& Beck (I968) and Beck \& Stanford (1968). The results obtained with unabsorbed antisera were confirmed by absorption tests.

On the basis of the evidence presented it is concluded that all the test strains were of one species, to members of which the names Mycobacterium friedmannii, M. abscessus, $M$. runyonii and $M$. borstelense have been applied.

Mycobacterium friedmannii was the name given by Holland (1920) to strains isolated from extensive lesions of two turtles by Friedmann (1903 $a, b)$ which had previously been known as 'turtle tubercle bacilli'. Moore \& Frerichs (I953) described as $M$. abscessus a strain isolated from the knee joint of a patient with chronic arthritis thought at first to have been tuberculous, and from injection abscesses following treatment with streptomycin in the same patient. $M$. runyonii was the designation given by Bojalil, Cerbón \& Trujillo (1962) to strains isolated from sputum and from an hepatic abscess. $M$. borstelense and its nicotinic acid producing variant were 
described by Bönicke (1964) and Bönicke \& Ewoldt (I965) who applied this name to strains isolated from sputum and gastric washings of patients with pulmonary lesions.

Mycobacterium friedmannii is undoubtedly the oldest of the names but there has been some controversy about the authenticity of the available strains now bearing this name. Until fairly recently the ATCC and the NCTC both listed strains of $M$. friedmannii. Following the work of Gordon \& Smith (1953, I955) who showed that the two strains in the ATCC were $M$. smegmatis and the strain 946 in the NCTC was $M$. fortuitum, the ATCC strains have been withdrawn and the NCTC strain is now listed as $M$. fortuitum. Nevertheless, there is a considerable body of published evidence, both serological (Wilson, 1925; Mudd, 1925; Furth, 1926; Furth \& Aronson, 1926; Griffith, 1930) and biochemical (Gordon, 1937; Gordon \& Hagan, 1938), that $M$. friedmannii differs from $M$. ranae (fortuitum), $M$. smegmatis and other mycobacteria. These findings and our results with the strain NCTC 946 , strongly suggest that this strain, and not those identified by others as $M$. smegmatis, is the true representative of Friedmann's strains.

We therefore consider that the appropriate designation for the species represented by our eight test strains is Mycobacterium friedmannii Holland, and that the term niacinogenes should be retained for the variant which produces nicotinic acid. The names of $M$. abscessus, $M$. borstelense and $M$. runyonii are synonyms for the species and should be discarded.

Our results agree with those of Bönicke \& Stottmeier (1965) who found Mycobacterium borstelense to differ in phage susceptibility and in a number of biochemical tests from $M$. ranae (fortuitum), and with those of Takeya, Nakayama \& Nakayama ( 1967 ) who distinguished between $M$. runyonii and $M$. ranae (fortuitum) by biochemical and cross-sensitivity skin tests. Tsukamura (1967), on a basis of numerical taxonomy, also concluded that $M$. runyonii and $M$. ranae (fortuitum) were different. He considered, however, that these differences justified the classification of $M$. runyonii only as a subspecies of $M$. ranae (fortuitum), not a separate species. Tsukamura, Tsukamura \& Mizuno (1967) also found M. abscessus and the strain NCTC 946 (which they received under the designation of $M$. fortuitum) to be the same as $M$. runyonii. The strain NCTC 946 was also found by Marks \& Szulga (1965), who analysed the lipid chromatography pattern of mycobacteria, to differ in this respect from other strains of $M$. ranae (fortuitum) that they examined. Our conclusion that $M$. borstelense is identical with $M$. abscessus and $M$. runyonii is, however, at variance with the views of Tsukamura, Mizuno \& Tsukamura (I968) who consider it to be a separate species. Although $M$. friedmannii differs taxonomically from $M$. ranae (fortuitum) the two species are similar in habitat and in their significance as potential pathogens. The finding of $M$. friedmannii in a water tank shows that like $M$. ranae (fortuitum), this organism can occur elsewhere than in animals. Both species are opportunist organisms which under certain circumstances give rise to lesions in poikilothermic animals and in man.

We thank Dr P. Inman and Mr A. E. Brown for permission to report on the two strains isolated from injection abscesses in Hartlepool, Dr R. Muser (Tierhygienisches Institut in Heidelberg), for the supply of the two strains of $M$. borstelense, and Dr E. H. Runyon of the Veterans Administration, Salt Lake City, Utah, for arranging for us to receive the type strain of $M$. abscessus. Mrs S. Hunnes and $\mathrm{Mr}$ W. J. Gunthorpe gave valuable technical assistance. 


\section{REFERENCES}

BeCK, A. (1965). Mycobacterium fortuitum in abscesses of man. J. clin. Path. 18, 307.

Beck, A. \& StANFord, J. L. (1968). Mycobacterium xenopei: a study of 16 strains. Tubercle, Lond. 49, 226.

Bojalil, L. F., Cerbón, J. \& Trujillo, A. (I962). Adansonian classification of mycobacteria. J. gen. Microbiol. 28, 333 .

BöNICKE, R. (1962). Identification of mycobacteria by biochemical methods. Bull. Un. int. Tuberc. 32, 13.

BönICKe, R. (1964). Beschreibung der neuen Species $M$. borstelense n.sp. Zentbl. Bakt. ParasitKde (Abt I) I96, 535 .

BöNICKE, R. \& EwOlDT, A. (1965). Quantitative Untersuchungen über das Niacinbildungsvermögen von Mycobacterium borstelense var. niacinogenes. Beitr. Klin. Tuberk. 130, I49.

Bönicke, R. \& StotTMEIER, D. (1965). Erkennung und Identifizierung von Stämmen der Species Mycobacterium borstelense. Beitr. Klin. Tuberk. 130, 210.

Boyden, S. V. \& Sorkin, E. (1955). A study of antigens active in the tannic acid haemagglutination test present in filtrates of culture of Mycobacterium tuberculosis. J. Immun. 75, 15.

FriedmanN, F.F. (1903a). Spontane Lungentuberkulose bei Schildkröten und die Stellung des Tuberkelbazillus im System. Z. Tuberk. 4, 439.

FriedmanN, F. F. (1903b). Der Schildkrötentuberkelbazillus, seine Züchtung, Biologie und Pathogenität. Zentbl. Bakt. ParasitKde (Abt I) 34, 647, 793.

FURTH, J. (1926). On the serological relationship of acid-fast bacteria. J. Immun. 12, 273.

Furth, J. \& Aronson, J. D. (1926). On the specificity of the alcohol soluble substances of acid-fast bacteria. J. Immun. 13, 265.

Gordon, R. E. (1937). The classification of acid-fast bacteria. J. Bact. 34, 6I 7 .

Gordon, R. E. \& HaGan, W. A. (1938). The classification of acid-fast bacteria. II. J. Bact. 36, 39.

GoRdon, R. E. \& SMITH, M. M. (1953). Rapidly growing, acid fast bacteria. I. Species descriptions of Mycobacterium phlei Lehmann and Neumann and Mycobacterium smegmatis (Trevisan) Lehmann and Neumann. J. Bact. 66, $4 \mathrm{I}$.

Gordon, R. E. \& Sмrth, M. M. (I955). Rapidly growing, acid fast bacteria. II. Species description of Mycobacterium fortuitum Cruz. J. Bact. 69, 502.

Griffith, A. S. (1930). A System of Bacteriology. Ch. V. Tuberculocis in cold-blooded animals. 5, 326. London: H.M.S.O.

Holland, D. (I920). Final report of the Committee of the Society of American Bacteriologists on characterization and classification of bacterial types. J. Bact. 5, 224.

Inman, P., Brown, A. E., Beck, A. \& Stanford, J. L. (I969). An outbreak of injection abscesses due to Mycobacterium abscessus. Arch. Derm. (In the Press.)

MARKS, J. \& Richards, M. (1962). Classification of the anonymous mycobacteria as a guide to their significance. Mon. Bull. Minist. Hlth. 21, 200.

MarKs, J. \& Szulga, T. (I965). Thin-layer chromatography of mycobacterial lipids as an aid to classification. Technical procedures; Mycobacterium fortuitum. Tubercle, Lond. 46, 400.

MiddlebrooK, G. (1954). Isoniazid resistance and catalase activity of tubercle bacilli. Am. Rev. Tuberc, pulm. Dis. 69, $47 \mathrm{I}$.

MoOre, M. \& Frerichs, J. B. (I953). An unusual infection of the knee with subcutaneous abscesslike lesions of the gluteal region. $J$. invest. Derm. 20, 133 .

Mudd, S. (1925). A study by new methods of the surfaces of normal and sensitised acid-fast bacteria. Proc. Soc. exp. Biol. Med. 23, 569.

Stanford, J. L. \& Beck, A. (1968). An antigenic analysis of the mycobacteria. J. Path. Bact. 95, I3I.

StANFord, J. L. \& Gunthorpe, W. J. (1969). Serological and bacteriological investigation of Mycobacterium ranae. J. Bact. 88, 375 .

TakeYA, K., NAKayama, Y. \& NaKayama, H. (1967). Relationship between Mycobacterium fortuitum and Mycobacterium runyonii. Am. Rev. resp. Dis. 96, 532.

Tsukamura, M. (1967). Identification of mycobacteria. Tubercle, Lond. 48, 311 .

Tsukamura, M., Tsukamura, S. \& Mizuno, S. (1967). Numerical taxonomy of Mycobacterium fortuitum. Jap. J. Microbiol. Ir, 243. 
TSuKamura, M., Mizuno, S \& Tsukamura, S. (1968). Classification of rapidly growing mycobacteria. Jap. J. Microbiol. 12, I5I.

ViRTANEN, S. (1960). A study of nitrate reduction by mycobacteria. The use of the nitrate reduction test in the identification of mycobacteria. Acta tuberc. scand. suppl. 48, I.

WAYNe, L. (I962). Differentiation of mycobacteria by their effect on Tween 80. Am. Rev. resp. Dis. 86, 579 .

WhITEHEAD, J. E. M., WiLDY, P. \& ENGBAEK, H. C. (1953). Arylsulphatase activity of mycobacteria. J. Path. Bact. 65, $45 \mathrm{I}$.

WILsON, G.S. (1925). The serological classification of the tubercle bacilli by agglutination and absorption of agglutinins. J. Path. Bact. 28, 69.

\section{Note added in proof}

Since the submission of this paper Dr E. H. Runyon has drawn our attention to the fact that this designation Mycobacterium friedmannia does not comply with the International Code of Nomenclature of Bacteria and Viruses. The Index Bergeyana lists this organism as Mycobacterium chelonei. This designation was used by Bergey et al. in the first edition of their Manual (1923). 